\title{
La movilización populista: ¿cómo y cuándo nace en Perú?
}

\author{
Reseña: Jansen, R. (2017) Revolutionizing Repertoires. The rise of Populist \\ Mobilization in Peru. Chicago: Chicago University Press.
}

\section{Verónica Calvopiña Panchi}

$\mathrm{L}$ a movilización populista no es propia de la cultura política de América Latina, ni era parte del accionar político de la región en el siglo XIX, ni a inicios del XX. Esta es una de las principales ideas que propone Robert S. Jansen en su libro Revolutionizing Repertoires. The rise of Populist Mobilization in Peru. Allí se analizan las elecciones presidenciales de 1931 como el momento en que la movilización populista se cristaliza. En dichas elecciones participaron el coronel Luis Sánchez Cerro, y el líder sindical Víctor Haya de la Torre, ambos provenientes de familias de clase media y no de la aristocracia, nacidos en provincia y no en la capital, Lima. Estas características eran nuevas entre los actores políticos que hasta ese momento habían alcanzado la presidencia en Perú. Pero, sobre todo, es su accionar, y su capacidad de movilizar a otros sectores sociales lo cambiará el panorama político dominante en este país andino.

Jansen, en su obra, va a dar cuenta, entre otras cosas, de cómo se había configurado el régimen político tras la independencia española. Se analiza el contexto que permitió el aparecimiento político de Sánchez Cerro y Haya de la Torre; y, finalmente, se escrudiñan las acciones desarrolladas por ambos políticos que, según el autor, cambiaron lo que denomina 'el repertorio político' de Perú. Esta reseña hablará de los elementos que Jansen identifica como constitutivos de la movilización populista y que la elevan como nueva opción política usada por ambos candidatos presidenciales en 1931. Finalmente, se evalúa la utilidad del modelo teórico propuesto por el autor para estudiar otros momentos de movilización política en la región. 


\section{Los primeros repertorios en la política peruana}

Jansen parte de realizar un repaso a los repertorios políticos que dominaron la política peruana antes de la llegada de la movilización populista. Así, tras la independencia, la vida política en Perú era manejada por caudillos militares y locales que basaban su liderazgo en la victoria de campañas militares y se mantenían gracias a redes clientelares. Aunque en ese entonces no existieron partidos políticos de carácter nacional, se desarrollaban elecciones que limitaron la influencia de las élites y permitían el liderazgo local indígena, dejando el terreno libre para que la iglesia y el ejército sean las instancias que acercaban al gobierno con las localidades. Esta primera práctica política cambia a partir de 1840 cuando la explotación del guano favorece al enriquecimiento de una élite liberal que comienza a manejar la vida política y económica del país. Se forman los primeros clubes y partidos políticos -el Partido Civil y el Partido Demócrata- que tendrían influencia local y nacional. El caudillismo del periodo anterior da paso a una práctica política dominada por las élites y caracterizada por el clientelismo, la corrupción electoral, junto con una movilización popular agresiva y violenta que buscaba controlar los resultados electorales.

Este período es conocido como la República Aristocrática y fue dominado por el Partido Civil. El último presidente de este período fue Augusto Leguía (examinado en el Capítulo 3), quien llegó dos veces a la presidencia: la primera bajo el auspicio de los grupos políticos tradicionales, y la segunda ocasión, que duró once años, con el respaldo popular de sindicalistas y estudiantes. El Oncenío de Leguía terminaría con una insubordinación militar, donde se destaca la presencia del coronel Luis Sánchez Cerro, quien canalizaría el derrocamiento de Leguía a su favor, erigiéndose así como una nueva figura en la escena política. Aunque en su 
segundo mandato Leguía llega con apoyo social, prontamente iba a caer en las viejas prácticas represivas, autoritarias y de alianza con las élites conservadoras, descartando así una movilización populista a su favor.

La práctica política de la República Aristocrática, según señala Jansen, usó la participación social de forma clientelar y estuvo basada en pactos. Por tanto, asegura el autor, la etapa caudillista fue más popular que la fase aristocrática aunque, finalmente, las dos mantuvieron el poder en unos pocos. En este marco, sin embargo, aparecen diversas demandas sociales, articuladas en organizaciones sindicales y estudiantiles que lideraron procesos de movilización popular. Estos grupos aparecen en la política peruana disputando las prácticas políticas elitistas y excluyentes, y su presencia va a contribuir al quiebre de la República Aristocrática y al aparecimiento de la movilización populista.

\section{La movilización populista: su ascenso en Perú}

Robert S. Jansen inicia su libro definiendo la movilización populista como la práctica política que junta la movilización popular -entendida como la movilización de sectores marginados a la acción política-, y la retórica populista -es decir, la elaboración de un discurso anti-élite, nacionalista y que articula las demandas de varios grupos sociales.

Para Jansen, la movilización permite la retórica populista, y la retórica alienta la movilización popular. Sin embargo, una puede estar presente sin la otra, y ambas pueden variar dependiendo el lugar y sus contextos socioeconómicos. Únicamente cuando la práctica movilizadora impulsa y refuerza el discurso populista de un determinado proyecto político, nos encontramos frente a una movilización propiamente populista. 
En el caso de Perú, la movilización populista incorpora por primera vez a sectores campesinos, indígenas, trabajadores, en una contienda electoral en 1931, pero ¿cómo aparece esta movilización populista?

Jansen rastrea varios momentos en la historia peruana en que surgen actores y grupos sociales cuyas prácticas políticas resquebrajaron repertorios tradicionales (capítulo 3). Uno de estos momentos es el ascenso de Leguía por primera vez a la presidencia del país. Su propia figura ya significaba una ruptura con la tradición de gobernantes de ascendencia europea y limeños que habían gobernado anteriormente. En segundo lugar, y aunque llega con apoyo del Partido Civil, ya en el gobierno entra en confrontación directa con sus líderes; esto hará que luego de su mandato sea enviado al exilio, y que para su segundo gobierno forme su propio partido y se dedique a debilitar a los partidos tradicionales.

Otro de los actores que abonan en el quiebre de las prácticas políticas tradicionales en Perú son los sindicatos y los estudiantes. Ambos grupos apoyaron una huelga general para 1918, entablando así un nuevo momento político pues logran negociar con éxito sus demandas con el gobierno de turno. Jansen, sin embargo, no identifica como una movilización popular a estos eventos. La efervescencia tras la huelga es aprovechada por Leguía para ganar las elecciones con apoyo militar. Por su parte, los sindicatos y estudiantes lograrán que el nuevo gobierno cumpla con sus demandas, entre las que se cuenta la creación de universidades populares. Sin embargo, Leguía caería en prácticas autoritarias y posturas conservadoras, deteniendo a estudiantes y mandando al exilio al líder sindical-estudiantil Haya de la Torre.

Durante este período aparecen dos figuras que van a contribuir al pensamiento político peruano y latinoamericano, además de sumar en la construcción de una retórica populista desde la izquierda y los sectores populares. Se trata, por un lado, de José Carlos Mariátegui, quien plantea un socialismo indígena, expresado principalmente en la Revista Amauta, y 
habla de la construcción de una organización social a largo plazo. Por otro lado, Víctor Haya de la Torre quien, desde el exilio, fundó el APRA bajo la idea de movimiento pancontinental, con células en diferentes países. Aunque inicialmente ambos intelectuales tuvieron contribuciones mutuas, Mariátegui va a desencantarse de Haya de la Torre, pues considera que su acción se centra en lograr una victoria electoral que destituya al gobierno de Leguía, a más de tener una práctica personalista. Tras esta ruptura Mariátegui funda el Partido Socialista, posteriormente transformado en Partido Comunista.

Haya de la Torre desistiría de una acción golpista en contra de Leguía, no así el ejército y Luis Sánchez Cerro, quienes lograron el derrocamiento del dictador en agosto de 1930. La caída del gobierno de Leguía hace que Sánchez Cerro pase de ser un militar de rango medio a una de las figuras más aclamadas del país, gracias a que, entre otros motivos, difunde el Manifiesto de Arequipa, un documento que sustenta políticamente la acción militar contra Leguía. Sánchez Cerro dirige por seis meses la Junta Militar Provisional y luego es enviado al exilio por la cúpula militar. La Junta se reconstituye y llama a elecciones presidenciales tras la aprobación de una nueva ley electoral que permitiría, por primera vez, que los obreros, artesanos, comerciantes, y clases subproletarias puedan sufragar.

Para las elecciones de 1931 se construyen desde el exilio las candidaturas de Sánchez Cerro y Haya de la Torre. Sus partidarios en Perú ayudaron con la conformación y unificación de los partidos políticos de ambos candidatos: La Unión Revolucionaria, partido de Sánchez Cerro, y la Alianza Popular Revolucionaria Americana, APRA, de Haya de la Torre. Estos partidos se disputaron el apoyo de trabajadores y sectores populares, además de contar con clubes barriales, entre otras organizaciones locales. Esto amplió la participación política hacia sectores tradicionalmente excluidos y constituyó un cambio esencial en las prácticas políticas dominadas hasta ese entonces por las élites. Si antes los presidentes se 
elegían entre clubes exclusivos, desde 1931 la decisión sería tomada por el partido que más simpatizantes alcanzara en las calles. Había mitines y grandes eventos masivos no solo en Lima sino también en otras ciudades, donde la gente cantaba, llevaba pancartas y consignas. Según Jansen, aunque sin presentar un análisis a profundidad, en las consignas usadas se deja entrever un simbolismo patriótico que expresa lo nacional- popular (ver Capítulo 5).

En cuanto a la retórica usada por los candidatos durante los mitines de campaña, estos recurrieron a elevar el sentimiento nacionalista y de inclusión entre la población empobrecida y migrante de Lima, y en los departamentos interiores. Ambos contendientes crearon, además, la figura de un enemigo: para Sánchez Cerro eran los partidarios de Leguía, mientras que, para Haya de la Torre, las élites económicas y políticas. Cada cual acusaba al otro de pertenecer al grupo enemigo. Jansen distingue un discurso más detallado en el candidato del APRA por su formación intelectual y sindical, elaborado durante su más de diez años de experiencia política; mientras que, el contendiente de la Unión Revolucionaria presentaba un discurso más conservador y patriarcal, construido apenas meses antes durante el derrocamiento a Leguía.

Por su parte, los partidos tradicionales llegaron debilitados por la persecución durante el Oncenio de Leguía (ver Capítulo 4). Las élites recurrieron a sus prácticas políticas tradicionales, puesto que la movilización populista significó un acercamiento a las masas, algo que para ellos era impensable. Sin embargo, pronto se movilizarían a favor de Sánchez Cerro, pues lo consideraban un personaje más maleable a diferencia de Haya de la Torre. En tanto, el Partido Comunista veía con desconfianza los alcances de la movilización populista en términos revolucionarios. Siguiendo las ideas de la Internacional Comunista, pensaban que Perú estaba listo para una insurrección popular y que, por tanto, era innecesario pactar con otros grupos políticos como el APRA. Para Jansen, ambos partidos tuvieron una 
pobre lectura del contexto, lo que no les permitió innovar políticamente y ver de manera potencial la movilización populista; pero, por otro lado, esto permitió que el APRA y la Unión Revolucionaria se impulsaran en esta contienda.

\section{Modelo para analizar el populismo}

Otra de las preguntas realizadas por el autor del libro es saber por qué la movilización populista se gestó en Perú, antes que en cualquier otro país latinoamericano con un movimiento obrero más fuerte, como Argentina. Como revisamos, Perú pasó de tener gobiernos autoritarios, de élite, con prácticas políticas clientelares y limitadas, a tener dos candidatos presidenciales, considerados, hasta ese momento, 'outsiders' en la política peruana. Estos candidatos comprendieron que necesitaban incursionar con otras formas de movilización en la campaña presidencial y lo hicieron usando una retórica más cercana a los problemas de la gente, que aludía además a su identidad indígena o provinciana, algo que no se había usado anteriormente (capítulo 6).

El Perú de la década de 1930 era un país con tradición conservadora, el crecimiento de Lima atrajo a migrantes del interior del país, se formaron barrios populares, creció también la burocracia. Fue esta población la que apoyó las candidaturas de Sánchez Cerro y Haya de la Torre: a ella se dirigieron sus discursos y acciones. Es en este contexto que aparece la movilización populista. Para Jansen, aunque esta práctica era nueva, en los repertorios políticos incorporó aspectos que eran ya conocidos para la sociedad peruana. Los mitines parecían procesiones, se abandonó el clientelismo por las recompensas a los seguidores del partido, entre otras acciones. Tras las elecciones de 1931, la movilización populista quedó 
instituida en los repertorios políticos peruanos; y, aunque se replica en campañas electorales posteriores, sus prácticas no se innovan y, por tanto, finalmente se consolidan como un modelo político tradicional, aunque no el único.

El autor señala que para una práctica política se convierta en parte del repertorio es necesario que surja como respuesta creativa e innovadora a un momento conflictivo y que modifique sustancialmente las prácticas políticas dominantes. Luego, debe ejecutarse y difundirse hasta convertirse en familiar para el escenario político. La movilización populista inicia como parte de la campaña electoral en 1931 en Perú. Posteriormente sería usada por diferentes actores políticos, bajo diferentes retóricas democráticas o autoritarias, relacionadas tanto con la izquierda como con la derecha. Una historia similar se encuentra en otros países de América Latina, donde está práctica surge como opción ante los gobiernos militares, caudillistas, de élite y autoritarios, pero también frente a las prácticas que presentaban los movimientos de izquierda en la región.

Al ser la movilización populista una práctica adaptable a diferentes ideologías y estilos de gobierno, Jansen sugiere que, para analizar las experiencias de movilización populista en otros países -no solo latinoamericanos-, primero, es necesario dejar de hablar de 'populismo', al ser un término más relacionado con un pensamiento nacionalista y fascista; y, segundo, explotar la capacidad descriptiva del término 'movilización populista' que permite analizar mejor los contextos en que estas prácticas se desarrollan, sus objetivos y consecuencias. 
